\title{
Reformas de laicização do Estado e da Sociedade na ação governativa de Afonso Costa no início da 1a República portuguesa (1911 e 1913)
}

\author{
Reforms of State and Society laicization in Afonso Costa government action in the \\ beginning of the portuguese first Republic (1911 and 1913)
}

\author{
Jorge Pais de Sousa \\ Doutor em História \\ Investigador do CEIS20 da Universidade de Coimbra \\ jorgepaissousa@netcabo.pt
}

\begin{abstract}
Resumo: Em dois governos diferentes que integrou, ou presidiu, Afonso Costa (18711937) introduziu na sociedade portuguesa um conjunto de reformas estruturantes, com vista à sua laicização e à criação de um Estado e de uma nação modernos. Enquanto ministro da Justiça do Governo Provisório da República decretou, no mês de fevereiro o registo civil obrigatório, e, em abril de 1911, a lei de Separação do Estado das Igrejas. Estes decretos serão, posteriormente, ratificados pela Assembleia Constituinte de 1911. Em julho de 1913 cria o Ministério da Instrução Pública, mas agora na qualidade de presidente do Governo. Analisar a programática política e doutrinária que está subjacente ao teor destes diplomas, de forma a realizar estas reformas cruciais para um Estado e uma nação modernos no Portugal do início do século XX, pelo também professor catedrático de Organização Judiciária, é o objetivo central deste breve ensaio.
\end{abstract}

Palavras-chave: Intelectuais e as reformas de laicização em Portugal, Registo civil obrigatório, Lei de Separação do Estado das Igrejas, Ministério da Instrução Pública.

\begin{abstract}
In two different governments that joined or chaired, Afonso Costa (1871-1937) introduced in the Portuguese society a set of structural reforms, with a view to secularization and the creation of a state and a modern nation. As justice minister of the Provisional Government of the Republic decreed in February compulsory civil registration, and in April 1911, the law of the Church's State Separation. These decrees will be subsequently ratified by the Constituent Assembly of 1911. In July 1913 establishing the Ministry of Education, but now as President of the Government. Analyse programmatic policy and doctrine that underlies the content of these regulations in order to carry out these crucial reforms to a state and a modern nation in Portugal of the early twentieth century by also Professor of Judicial Organization, it is the main objective of this small essay.
\end{abstract}

Keywords: Intellectuals and the laicization reforms in Portugal, Compulsory civil registration, Law of Churches State Separation, Ministry of Education. 
O fenómeno da laicização do Estado e da sociedade durante a 1. ${ }^{a}$ República (19101926) constitui, só por si, um tópico complexo e vasto, no âmbito da historiografia contemporânea portuguesa do século XX. Neste sentido, e de modo a delimitar a problemática, o ângulo de abordagem que escolhemos inscreve-se na História do Direito e, em concreto, abordamos três diplomas legais que vistos no seu conjunto permitem, situar e enquadrar, o autor desta legislação no contexto da História Intelectual e Política. No plano analítico, procedemos a uma espécie de desconstrução historiográfica desta legislação, com vista a identificar os fundamentos políticos e doutrinários que lhe estão subjacentes, numa ótica da relação dos intelectuais com o exercício do poder.

Em termos de história comparada, e porque a questão da laicização se coloca primeiro na 1. ${ }^{a}$ República brasileira (1889-1930), designadamente, com a consagração no texto da Constituição da República dos Estados Unidos do Brasil de 1891 do princípio constitucional da separação entre o Estado e a Igreja Católica, importa passar em revista as consequências jurídico-políticas que elas tiveram na sociedade brasileira. O Estado deixou de ser confessional, ou seja, deixou de ter uma religião oficial. E, assim sendo, o governo brasileiro não interfere mais na escolha e nomeação dos responsáveis do alto clero, como o fazia em relação aos bispos e cardeais brasileiros. Por outro lado, as eleições deixaram de ter lugar dentro das igrejas. A paróquia, enquanto unidade administrativa, que poderia corresponder por exemplo a um município, foi extinta. E o monopólio do registo civil passa para o Estado em definitivo, o que permitiu proceder à criação de cartórios para proceder ao registo dos nascimentos, casamentos e da morte de todos os cidadãos brasileiros. Também os cemitérios públicos foram instituídos para permitir que qualquer pessoa fosse neles sepultada, independentemente do seu credo religioso. $\mathrm{O}$ Estado brasileiro também assumiu, de forma definitiva, o domínio das rédeas da educação instituindo várias escolas públicas dentro dos vários níveis de educação.

Regressando agora à realidade política, jurídica e social portuguesas, consideremos três fases distintas dentro deste processo progressivo de laicização do Estado e da sociedade. A primeira fase consiste no facto de Afonso Costa (1871-1937), na qualidade de ministro da Justiça do Governo Provisório, decretar, no mês de fevereiro de 1911, a lei do Registo Civil Obrigatório. E no mês de abril promulga a lei de Separação do Estado das Igrejas. Estes dois decretos serão, posteriormente, ratificados pela Assembleia Constituinte que está na origem da Constituição Política da República Portuguesa de 1911 (CP, 1992:191-193). A terceira fase tem lugar em julho de 1913, 
durante o primeiro governo a que Afonso Costa preside em acumulação com a pasta das Finanças, sendo nesta altura que é decretada a criação do Ministério da Instrução Pública.

Como já foi referido não nos interessa tanto a análise destes diplomas, mas antes proceder à identificação da natureza política e doutrinária que está subjacente ao teor desta legislação da autoria de Afonso Costa, cujos princípios fundamentais, apesar das diferentes transformações políticas pelas quais Portugal passou ao longo do século XX, jamais serão revogados e incorporam hoje o seu património político e jurídico. E isto porque os mais diferentes e recentes estudos publicados, sobre a lei do Registo Civil Obrigatório e da Separação do Estado das Igrejas, por estranho que pareça, nunca recorrem às teses e trabalhos universitários de Afonso Costa para entenderem os fundamentos jurídico-políticos destes diplomas da sua autoria, o qual, recorde-se, era professor catedrático de Organização Judiciária da Faculdade de Direito da Universidade de Coimbra quando é nomeado, a 5 de outubro de 1910, ministro da Justiça do Governo Provisório da República. O mesmo é válido para entender o diploma que cria, em 1913, o Ministério da Instrução Pública. ${ }^{1}$

\section{0 registo civil obrigatório}

A História do Direito do século XX em Portugal é marcada, em grande medida, pelo que os seus historiadores designam de época do direito social. ${ }^{2} \mathrm{E}$ do ponto de vista da história comparada reconhecem também que na Europa é a I Grande Guerra (19141918) que inaugura este tempo, devido às transformações políticas, económicas, sociais e tecnológicas que o conflito trouxe consigo e que o direito vai consagrar.

Recorde-se que, anteriormente, o pensamento europeu, durante o trânsito do século XVII para o século XIX, fora marcado por duas fases distintas: a primeira é caraterizada pela "atitude crítica ao Iluminismo e durante a qual se desenvolveram os movimentos de Contra-Revolução, do Romantismo e do Idealismo alemão; a segunda fase, cujo ponto de partida se faz coincidir, simbolicamente, com a morte de Hegel, em 1831, em que se assiste à reentrada dos princípios da Revolução e iluminísticos, favorecidos pelo condicionalismo histórico. Cabe recordar a evolução económica, o

\footnotetext{
${ }^{1}$ Ver esta ausência de referências aos escritos universitários de Afonso Costa nos mais diferentes autores, por exemplo, sobre a lei da Separação do Estado das Igrejas e pela ordem mais recente de publicação, os seguintes títulos: MATOS, 2011; SEABRA, 2009; MOURA, 2004; CATROGA, 1991.

${ }^{2}$ Cf. Época do Direito Social, em COSTA \& MARCOS, 2012.
} 
triunfo da burguesia e os progressos das ciências naturais" (COSTA \& MARCOS, 2010: 431). Por isso, e na perspetiva dos historiadores do direito, vigorou durante esta temporalidade, a época do individualismo político e do liberalismo económico. É ainda de registar que foi neste contexto que se assistiu ao desenvolvimento de um importante movimento de codificação jurídica em diferentes países europeus, o qual se vai comunicar a outros continentes. Movimento de codificação que se traduziu, pois, na "elaboração de amplos corpos legislativos unitários, obedecendo a uma orgânica mais ou menos científica e que condensavam, autonomamente, as normas relativas aos ramos básicos do direito, já então individualizados" (COSTA \& MARCOS, 2010: 462).

O que verificamos é que, em Portugal, a instauração da República antecipa o início da época do direito social, ou, no dizer assertivo de Rui de Figueiredo Marcos, funciona como a sua "antecâmara" (COSTA \& MARCOS, 2010: 537), pelo que a participação de Portugal no primeiro conflito à escala mundial, designadamente, a partir da declaração de guerra da Alemanha a Portugal de 9 de março de 1916, vem acelerar e aprofundar este conjunto de transformações. E o protagonista destas transformações jurídico-políticas na sociedade e no Estado portugueses é o ministro da Justiça do Governo Provisório. Na verdade, Afonso Costa tinha um perfil único para o desempenho destas funções governativas. Isto porque, por um lado, reunia as qualificações académicas de um professor catedrático de Organização Judiciária que lhe permitiam ter uma visão de conjunto de todo o sistema judiciário português e, por outro, possuía a experiência política de ter sido deputado pelo Partido Republicano Português (PRP) durante a Monarquia, ao longo de três legislaturas, a de 1900, 1906-1908 e 1908-1910, que lhe permitem encetar um programa de reformas jurídicas profundas e de largo alcance no Estado e na sociedade portuguesas. O facto de ter sido um deputado brilhante no parlamento monárquico permitiu-lhe alcançar uma notoriedade política muito significativa, dentro do PRP, que o leva a integrar o seu diretório.

A primeira grande iniciativa legislativa de cariz laicizador que Afonso Costa promulga é a lei do Registo Civil, enquanto ministro da Justiça, a qual assume a forma de “decreto com força de lei” e tem data de 18 de fevereiro de 1911, cuja novidade é a de impor o registo civil obrigatório para todos os cidadãos portugueses. Integra 365 artigos redigidos de uma forma bem objetiva. Antes, porém, a 25 de dezembro de 1910, legislara em matéria de leis de família: primeiro com a lei do casamento como contrato civil e, em 
seguida, com a lei de proteção dos filhos. O que significa que, em abril de 1911, a República Portuguesa fica dotada de um Código do Registo Civil e Leis da Família. ${ }^{3}$

Trata-se de uma lei que é estruturante do Estado republicano, pois é a base jurídica em que assentam os direitos civis do cidadão português, como o indica o disposto no seu artigo 1. ${ }^{\circ}$, a saber: "O registo civil, que o Estado institui por este decreto com força de lei, destina-se a fixar autenticamente a individualidade jurídica de cada cidadão e a servir de base aos seus direitos civis" (CRCR, 1911: 3).

Como escreveu, em síntese, Jaime Botelho Antunes, na década de 70 do século $\mathrm{XX}$, o indivíduo entra no mundo jurídico com o nascimento

...e passa a ocupar nesse mundo um determinado estado, mais ou menos mutável: o seu estado civil. Abre-se este com o nascimento e completa-se ou modifica-se pela sucessão de factos que ocorrem na vida desse indivíduo, casa-se, divorcia-se, emancipa-se, é adotado, perfilhado, enviúva, morre. O Estado entendeu ser do interesse público e do interesse particular que esse estado civil de cada um pudesse ser conhecido a todo o momento, por quem nisso tivesse interesse. Confiou então à sua administração, o encargo de elaborar um instituto, um sistema que tivesse por escopo anotar esses factos da vida de cada um, que constituem e integram o seu estado civil em todo e qualquer momento. E conseguiu esse intuito com os registos, que são documentos onde se inscrevem precisamente esses tais factos, aqueles que o legislador entendeu em haver episodicamente vantagem em registar. Para se lavrar e guardar esses registos, foram criadas as Conservatórias, locais aonde os interessados se dirigem, ou para declararem as alterações que surgem no seu estado civil ou para que lhes seja indicado esse seu estado ou o de qualquer pessoa (ANTUNES, 1970:4).

E se, no entendimento do legislador, a fixação da individualidade jurídica de cada cidadão serve de base aos seus direitos civis, compreende-se a razão da sua

\footnotetext{
${ }^{3}$ É de registar que este primeiro Código de Registo Civil da República é organizado por Germano Martins (1871-1950). Este era diplomado em Direito pela Universidade de Coimbra (1897) e repartiu a sua vida, entre o exercício da advocacia com Afonso Costa, no Porto e em Lisboa, e a carreira como jurista e funcionário público. Afonso Costa publicou em coautoria com Germano Martins, pelo menos os seguintes dois títulos jurídicos: COSTA \& MARTINS, 1903; COSTA \& MARTINS, 1906. Acresce que, do ponto de vista político, Germano Martins foi sempre uma figura muito próxima de Afonso Costa e, tal como ele, membro do PRP. A nomeação de Afonso Costa para ministro da Justiça fez com que este o tornasse seu colaborador em Lisboa. Germano Martins torna-se secretário geral e depois é diretor geral do Ministério da Justiça entre 1911 e 1935, até ser demitido por Salazar. Antes, em 1925, foi ministro do Interior.
} 
obrigatoriedade para obedecer ao princípio da igualdade de todos perante a lei, tal com prescreve o art. 2.: "É obrigatória a inscrição no registo civil dos factos essenciais relativos ao indivíduo e à família, e à composição da sociedade, nomeadamente dos nascimentos, casamentos e óbitos" (CRCLF, 1911: 3).

E passa a ser competência do conservador de registo civil, que é nomeado pelo Ministério da Justiça "de entre bacharéis formados em direito, devidamente habilitados" (CRCLF, 1911: 4), proceder à função de lavrar os registos referentes aqueles factos que aconteceram na esfera civil de cada indivíduo, e conservá-los, para, a todo o momento, eles servirem de prova desse estado civil (cf. ANTUNES, 1970: 4). Portanto, em obediência estrita ao Código do Registo Civil, cabe ao conservador registar, atualizar ou completar o tipo de registos de caráter civil anteriormente mencionados e que constam dos textos dos registos, bem com cobrar os emolumentos que custam essa tipologia de registos. Por outro lado, é atribuída uma competência territorial a cada Conservatória, a qual coincide com a do município, firmada sobretudo na comodidade de deslocação dos declarantes e interessados. ${ }^{4}$

Porém, tudo isto que hoje nos parece normal, pois incorpora o património da ordem jurídica e política portuguesa, foi há um século atrás uma medida legislativa fraturante, uma vez que retirou à Igreja Católica esta atribuição de fazer os assentos paroquiais para a maioria da população que professava o catolicismo e que, decorrente do seu magistério, registava os assentos de batismo, casamento e de passamento. Neste sentido, todos aqueles que não professavam a fé católica tinham de pagar este tipo de registos. É que, de acordo com o artigo $6^{\circ}$ da Carta Constitucional da Monarquia Portuguesa de 1826, que volta a ser reposta na sequência do golpe de Costa Cabral de 1842 até à implantação da República a 5 de outubro de 1910, o Estado português era confessional, nos seguintes termos: “A Religião Católica, Apostólica Romana continuará a ser a Religião do Reino. Todas as outras Religiões serão permitidas aos Estrangeiros com seu culto doméstico, ou particular, em casas para isso destinadas, sem forma alguma exterior de Templo" (CP, 1992:118).

Portanto, esta medida do ministro da Justiça Afonso Costa retira à Igreja Católica e ao clero, por um lado o desempenho de uma significativa função social e cultural junto das populações e, por outro, uma importante fonte de rendimentos. É que agora os registos

\footnotetext{
${ }^{4} \mathrm{O}$ art. $25 .^{\circ}$ dispõe que "Em cada concelho fora das capitais de distrito haverá um oficial de registo civil que funcionará na respetiva câmara municipal, ou em lugar apropriado por esta fornecido, e terá funções de registo em todas as freguesias do concelho (CRCLF, 1911:14).
} 
que se prendem com o nascimento, casamento e falecimento de todos os cidadãos portugueses, independentemente, do seu credo religioso, filiação política, ou estatuto social, passam a ser realizados nas Conservatórias do Registo Civil.

Em termos sociais, e num primeiro momento, este diploma revela-se uma iniciativa de caráter legislativo e político que afronta a hierarquia da Igreja Católica e suscita, no seio da sociedade portuguesa do início do século XX, uma enorme clivagem. Sobretudo, junto das populações que viviam fora dos centros urbanos e estavam ligadas ao setor primário e às atividades agrícolas e piscatórias, ou seja, a esmagadora maioria dos portugueses. Importa ter presente que, segundo o Censo da População de 1911, 76\% dos portugueses eram analfabetos. O que explica a importância política, social e até cultural da atividade do clero paroquial junto das populações do interior, pois, muitas vezes, só os párocos eram alfabetizados e, por conseguinte, detinham competências de escrita, leitura e cálculo, que lhe permitiam realizar os chamados assentos paroquiais ou até ensinar as primeiras letras. Não vamos abordar aqui o impacto político deste diploma na sociedade portuguesa, uma vez que existem diversos trabalhos publicados sobre esta matéria.

Todavia, e porque nenhum destes estudos aborda o pensamento jurídico-político do autor desta lei, é sobre este ângulo que pretendemos debruçarmo-nos. Na verdade, a lei do registo civil obrigatório vinha, em fevereiro de 1911, satisfazer uma velha aspiração de uma franja de indivíduos descatolizados que, desde a década de 70 do século XIX, promoviam o livre-pensamento e, consequentemente, reivindicavam a importância do Estado chamar para si o monopólio do registo civil, debaixo da bandeira da Associação Promotora do Registo Civil (cf. CATROGA, 1991: vol. II, p. 336). Sebastião de Magalhães Lima (1850-1928) é uma destas personagens que vem a assumir um papel destacado na promoção do registo civil obrigatório em Portugal, nomeadamente após 1911, quando esta agremiação muda de nome para Associação Propagadora da Lei do Registo Civil e assume a sua direção, com vista a auxiliar as autoridades da República a aplicar esta lei em todo o país. ${ }^{5}$

É de sublinhar que Magalhães Lima nasce no Rio de Janeiro, a 30 de maio de 1850, mas vem muito cedo com a família, aos quatro anos de idade, viver para a pequena localidade de Eixo, próximo da cidade de Aveiro, de onde os seus pais eram naturais e possuíam casa. No entanto, no seu livro de memórias que publica no final da sua vida e

\footnotetext{
${ }^{5}$ Sobre a sua figura e obra ver o livro de GARNEL, 2004.
} 
que, como ele diz, constitui um subsídio para a história do Partido Republicano Português (PRP), dedica um capítulo às suas origens brasileiras e, concretamente, elenca algumas das amizades que cultivou em vida, em Lisboa e Paris, com brasileiros notáveis, entre outros: Benjamin Constant, Campos Sales, Lopes Trovão - este encontra-o mais tarde em Paris quando ambos eram amigos do socialista Benoît Malon -, Silva Jardim, José do Patrocínio e Joaquim Nabuco, Assis Brasil, etc. ${ }^{6}$ Entre 1870 e 1875 conclui, com distinção, o curso de Direito na Universidade de Coimbra. Ao longo dos seus estudos jurídicos colabora em jornais conimbricenses de cariz literário, ao mesmo tempo que publica livros da sua autoria. Quando frequentava o quarto ano de Direito, e porque já se havia correspondido com Emilio Castelar que estava de visita a Coimbra, foi escolhido pela Academia para discursar e saudar em seu nome, com brilho e uma eloquência notáveis, o antigo presidente da $1 .^{a}$ República de Espanha - exerceu estas funções no breve período de 11 de fevereiro de 1873 e 29 de dezembro de 1874 -, e que era professor catedrático de História (cf. LIMA, 1985a: vol. I: 78-80). É também neste ano de 1874 que é iniciado na Loja Perseverança de Coimbra, com o nome simbólico de João Huss, a qual pertencia ao Grande Oriente Lusitano Unido (GOLU). E vem a ser eleito, em 1907, GrãoMestre do GOLU - que já então era a obediência maçónica maioritária em Portugal -, cujo cargo ocupa até ao fim da sua vida. Terminados os estudos instala-se em Lisboa, com o objetivo de fazer advocacia. A breve trecho, porém, descobre que o jornalismo é a sua profissão. Em Lisboa funda um dos jornais diários mais importantes portugueses de sempre que foi $O$ Século (1880-1977).

E é na qualidade dupla de diretor de $O$ Século e de advogado que, no ano de 1890 , quando da crise do Ultimato britânico, vem a Coimbra, a convite do então estudante de Direito, Afonso Costa, defendê-lo em tribunal, pois sob ele e o estudante de Medicina, António José de Almeida - este último foi defendido pelo futuro presidente da República Manuel de Arriaga -, pendia a acusação de abuso de liberdade de imprensa pelos artigos que publicaram no jornal $O$ Ultimatum. A defesa em tribunal foi tão bem conseguida que Magalhães Lima conseguiu a sua absolvição, ao contrário de Manuel de Arriaga que não evitou a condenação do estudante António José de Almeida a três meses de prisão. E porque é que o jovem Afonso Costa convida Magalhães Lima para seu advogado? É que, naquela altura, o estudante de Direito colaborava com $O$ Século noticiando neste jornal, através do envio de telegramas, factos relativos à vida universitária em Coimbra, além de

\footnotetext{
${ }^{6}$ Ver o capítulo seguinte: A minha origem brasileira e sua influência na minha vida, em LIMA, 1985: vol. I, pp. 27-31.
} 
que já existia entres os dois uma "afinidade", ou proximidade, do ponto de vista das ideias políticas. E a verdade é que se estabeleceu uma amizade e admiração recíprocas que viriam a perdurar ao longo das suas vidas. Veja-se, a propósito da questão da afinidade de ideias políticas entre ambos, o que escreveu Magalhães Lima no seu livro de memórias, em concreto no capítulo "Julgamento de Afonso Costa":

Afonso Costa combinou comigo uma maneira telegráfica de dar informações diárias sobre os exames finais na Universidade. Foi não só um grande serviço prestado ao jornal, senão também uma obra de decisivo alcance público. As nossas relações tornaram-se mais íntimas com este facto, além da afinidade de ideias que já existia entre nós. Em consequência dum artigo, publicado por ocasião do ultimatum inglês, que roubava uma parte do nosso território na província de Moçambique, foi Afonso Costa processado. O artigo em questão constituía um libelo famoso contra o Governo e o seu autor levou a amabilidade ao ponto de me convidar para o defender no tribunal...

Afonso Costa nunca esqueceu aquele dia, e muitas vezes me fala ainda na maneira como eu conduzi a defesa, que por igual impressionou estudantes e futricas.

Conto, pois, este facto, que me foi inspirado pela minha indignação contra o ultimatum, como um dos mais belos da minha vida de republicano (LIMA, 1985: vol. I: 152-153).

Por outro lado, o facto de Magalhães Lima ser um poliglota, notável para o seu tempo, permitia-lhe também viajar com grande facilidade pela Europa e participar em diversos congressos internacionais. É durante este trânsito e frequência impressionante de viagens e de participação em congressos internacionais que Magalhães Lima vem a conhecer pessoalmente Benoît Malon (1841-1893) e a tornar-se seu discípulo. Ao ponto de frequentar a redação em Paris e colaborar em La Revue Socialiste, fundada por Malon em 1885. Recorde-se que esta revista ainda hoje se publica em França, sendo o órgão do setor intelectual do Partido Socialista Francês (PSF). E é dessa relação que ele nos dá testemunho quando escreve sobre o fundador do socialismo integral, no segundo volume das suas memórias, o seguinte:

Amei Benoît Malon como se pode amar um apóstolo. Frequentei assiduamente a Revista Socialista, que ele dirigiu sapientemente, numa 
pequena sobreloja da Rue des Martyres, 8, Montmartre. Naquele improvisado cenáculo reuniam-se todos os sábados, além do Mestre, individualidades que depois representaram papel preponderante na política e nas letras francesas. Não deixarei de mencionar, entre outros: Georges Renard, mais tarde professor do Colégio de França; Gustave Rouanet, há pouco falecido, que se evidenciou como deputado, ao lado de Jaurès, um dos colaboradores da mesma revista; Eugène Fournière, publicista eminente, e Amilcare Cipriani, o famoso revolucionário italiano que se bateu ao lado de Garibaldi, etc. (LIMA, 1985: Vol. II: 33-34).

O que Magalhães Lima não refere no seu livro de memórias é que Benoît Malon escreveu e designou-o, no final da sua vida e no ano de 1890, como seu discípulo em Portugal. Esta informação está expressa no primeiro volume de Le Socialisme Intégral, ou seja, aquela que é a sua obra mais conhecida e fundadora desta corrente socialista, em: “Ansi se constitue ce que l'on pourrait appeler le socialisme professoral, riche déjà de noms et d'ouevres.... en Portugal, c'est le savant historien Oliveira Martins; c'est Bonança, c'est Téophile Braga, c'est Magalhães Lima...” (MALON, 1890: 205-206).

Não admira, pois, que dois anos mais tarde, em 1892, Malon escreve, a convite de Magalhães Lima, o prefácio para o seu livro O Socialismo na Europa. E por se tratar de um texto tão importante para a história da recepção desta corrente de pensamento socialista de matriz reformista em Portugal e também no Brasil que importa sublinhar que Malon publicou também este seu Une Préface, igualmente, em Paris, no segundo volume de La Revue Socialiste de 1892 (MALON, 1892, vol. 2: 79-86). É um texto de dez páginas muito importante na medida em que, a pedido de Magalhães Lima, Malon responde nele a três perguntas. A primeira pergunta feita por Magalhães Lima é a seguinte: "Qual é a nota dominante do socialismo na Europa? "O diretor da La Revue Socialiste responde aos leitores portugueses em que consiste o socialismo integral - também por ele designado como socialismo professoral - e como esta corrente socialista reformista se diferencia do socialismo revolucionário. Neste aspeto importa ter em conta a forma como Afonso Costa carateriza e interpreta, do ponto de vista teórico, o socialismo integral. Para este efeito, recorremos à sua tese de doutoramento A Igreja e a Questão Social, apresentada à Faculdade de Direito da Universidade de Coimbra em 1895, onde considera que o socialismo preconizado por Malon assenta em dois pilares estruturantes:

1. A doutrina económica de Marx; 
2. E no "Direito" e na sua expressão que é a Justiça. Por sua vez, os princípios da justiça social são a Liberdade e Igualdade (Cf. COSTA, 1895: 91-92).

Enquanto a terceira pergunta formulada por Magalhães Lima é a seguinte: “Qual deverá ser também a atitude dos republicanos, perante o movimento socialista atual?" (LIMA, 1892: 9-13). E a resposta de Malon consiste em citar 10 artigos de um pequeno volume de Teixeira Bastos intitulado "Projeto de um programa federalista radical para o partido republicano português". Preconiza Malon que, do ponto de vista tático, e nos países onde os socialistas integrais ou reformistas são minoritários, que estes devem integrar as formações partidárias republicanas, de forma a baterem-se, uma vez eleitos como deputados aos parlamentos nacionais, pela realização de reformas progressistas e de orientação socialista. Isto para dizer que entre as reformas que Malon cita da publicação referida de Teixeira Bastos, encontram-se diversas medidas de orientação socialista que o próprio Malon já preconizara quando da publicação, em 1891, do volume II de Le Socialisme Intégral: Des Reformes Possibles et des Moyens Pratiques. ${ }^{7}$ É neste livro e no Resumo Conclusivo Geral que encontramos, por exemplo, e de entre as diversas reformas preconizadas por Malon, avulta a do registo civil, nos seguintes termos: "Estado civil - Com tudo o que daí deriva, cadastro, notariado comunal, etc." (MALON, 1891: 446)

Portanto, e necessariamente para os socialistas integrais, o registo civil era algo que deveria ser concretizado ao nível municipal. E no caso português, e como se referiu antes, o legislador, cujo rosto já referimos que foi Afonso Costa, seguiu também o modelo francês e estipulou que as conservatórias de registo civil deveriam ser instituídas e funcionariam nas câmaras municipais.

Por último, refira-se que o prefácio escrito por Malon para abrir o livro de Magalhães Lima O Socialismo na Europa foi tão importante que o seu autor lhe dedica dez páginas para divulgar a sua obra, enquanto teórico do socialismo, apresentando-o aos leitores portugueses através de uma pequena biografia e depois chamando a atenção para o trabalho que ele vinha desenvolvendo na direção de La Revue Socialiste, cuja redação, como já sabemos, o próprio Magalhães Lima frequentava em Paris (Cf. LIMA, 1892: 260-269). A mesma atitude de escrever sobre a biografia do seu mestre socialista Benoît Malon vem Magalhães Lima a ter, no final da sua vida, quando escreve as suas memórias políticas, além de nelas voltar a publicar, novamente, o prefácio com que o teórico do

\footnotetext{
${ }^{7}$ Ver o capítulo “Résumé conclusionnel general”, em (MALON, 1891: 435-447).
} 
socialismo integral abre o seu livro que em 1892 escreveu sobre o tema do socialismo na Europa (Cf. LIMA, 1985: vol. II: 33-44).

Em suma, podemos dizer que Magalhães Lima e o seu livro $O$ Socialismo na Europa, prefaciado pelo próprio Benoît Malon, ocupam um lugar central na receção em Portugal das ideias socialistas integrais. Não é por acaso que mais tarde, três anos passados, Afonso Costa na sua tese de doutoramento A Igreja e a Questão Social cita este livro de Magalhães Lima por duas vezes (Cf. COSTA, 1895: 79-87). Algo muito importante, pois este é o único autor português que ele cita numa tese em que se declara socialista integral e expõe todo uma programática de ação política, com base naquela que Malon tinha exposto, quatro anos antes, no volume Le Socialisme Intégral: Des Reformes Possibles et des Moyens Pratiques. Nessa programática a observar pelos socialistas integrais, uma vez eleitos como deputados ao parlamento, consta esta medida, entre outras, em matéria de codificação de leis: "A refundição dos códigos, de modo a simplificá-los vezes" (COSTA, 1895: 96). Neste sentido, e a nosso ver, a publicação do Código de Registo Civil, logo em 1911 e após ter sido instaurada a República em Portugal, é uma medida política e jurídica fundamental, com vista a reunir e simplificar uma matéria decisiva para a consagração de todos os direitos civis dos cidadãos portugueses. Em síntese, a publicação da tese de doutoramento A Igreja e a Questão Social vem fazer de Afonso Costa o teórico português mais importante do socialismo integral, onde Malon e a sua obra são objeto de mais de 40 citações. Este facto foi reconhecido logo em 1899 , quando Heliodoro Salgado publica em Lisboa, os dois volumes da tradução portuguesa de $O$ Socialismo Integral.

Outro aspecto histórica e politicamente relevante é a reposta de Malon ao seu discípulo português Magalhães Lima, designadamente, a que se refere à atitude tática dos socialistas integrais perante o movimento republicano português. Malon configura nela um conjunto de orientações que aconselha a minoria de socialistas integrais a organizarem-se e a militarem dentro do PRP. A organização desta tendência minoritária denro do Partido Republicano foi algo que o historiador Norberto Ferreira da Cunha já tinha observado no seu estudo Benoît Malon e o Socialismo, onde escreve: "Até uma fração do Partido Republicano Português - sublinha - aderiu a este socialismo integral, ao contrário do Partido Socialista português que, apesar do admirável rigor científico do seu programa e da sua ortodoxia marxista... acabará por cair numa crise irremediável caso não enverede pela via reformista (CUNHA, 2010: 164). 
Por sua vez, e ainda sobre esta matéria de saber como se organizou esta "fração", ou tendência, de socialistas integrais dentro do PRP, dedicámos-lhe um estudo recente que ajuda a perceber as razões políticas e doutrinárias que estão na base da divisão no campo republicano que acontece dentro do Partido Republicano em 1911. Divisão de que resulta a transformação do PRP/Partido Democrático que passa a ser liderado por Afonso Costa, a criação do Partido Evolucionista Republicano de António José de Almeida, e, por último, a União Republicana de Brito Camacho (cf. SOUSA, 2015: 75-85).

Não menos importante é sabermos que a difusão das ideias socialistas de Malon no Brasil, designadamente junto de determinadas associações de operários e de alguns círculos de intelectuais brasileiros, foi feita através dos livros de Magalhães Lima, uma vez que não chegou a haver tradução e publicação no Brasil da obra do autor de Le Socialisme Integral. É isso que nos dão conta os diversos estudos do historiador Claudio Batalha, sobre a receção e difusão do socialismo integral no Brasil (BATALHA, 2007: vol. II: 9-41).

\section{A Lei da Separação do Estado das Igrejas}

Nesta sequência legislativa surge, a 20 de abril de 1911, o decreto com força de lei de Separação do Estado das Igrejas. Em linhas gerais, o que estabelecia este diploma (cf. MATOS, 2011)? Reconhecia, desde logo, plena liberdade de consciência a todos os cidadãos portugueses e aos estrangeiros que habitassem o território português. Por outro lado, a religião católica, apostólica, romana deixava de ser a religião do Estado, admitindo-se as diversas confissões religiosas, a título de agremiações particulares, contanto que não ofendessem a moral pública, nem os princípios do direito público português. A “'Lei da Separação', em determinados aspetos, tornou-se um diploma de incorporação, sobretudo no que tocava à integração do vasto património da Igreja no domínio público" (COSTA \& MARCOS, 2010: 50). E se a religião católica deixava de ser a religião oficial do Estado, então cessava também o seu financiamento. Nessa altura, os católicos podiam associar-se para angariarem os meios necessários ao sustento e prática do culto, pelo que o "catolicismo assumia o valor privado de um culto doméstico de alguns, a quem o Estado atribuía uma licença para a prática de cerimónias religiosas em catedrais, igrejas e capelas, que a própria lei declarava pertença e propriedade do Estado" (COSTA \& MARCOS, 2010: 50-51). 
Como dissemos no início não é este o momento para avaliar o impacto político e social deste diploma, pois já vários historiadores o fizeram. O que eles não referiram é o que é que o professor universitário Afonso Costa escreveu no tempo da Monarquia sobre esta matéria, ou seja, antes de se tornar ministro da Justiça do Governo Provisório da República em 1911 e ser o autor deste decreto-lei. Vejamos o que preconiza, em 1895, na sua tese de doutoramento A Igreja e a Questão Social: "A abolição das côngruas e das despesas com os ministros de qualquer religião, com separação das igrejas e do estado e a substituição das festas religiosas por festas cívicas de um alto caráter moral" (COSTA, 1895: 97-98).

Repare-se, pois, que numa altura em que se prepara para ser professor universitário e, portanto, bem antes de se candidatar sequer a deputado pelo Partido Republicano, pela primeira vez no ano de 1899, já tinha escrito num programa de ação política, inspirado pelas ideias do socialismo integral de Malon, a necessidade de lutar por uma lei de separação do Estado das diferentes igrejas. Sublinhe-se, ainda, que no texto de 1895 a palavra igreja surge escrita no plural. E por se tratar de um princípio de orientação política de laicização do Estado e da sociedade portuguesas, e se aquele deixava de ser confessional, decorria que também deixava de ter despesas com os “ministros de qualquer religião". E vamos encontrar este princípio reafirmado nas suas primeiras lições sobre Economia Política e que surgem logo em 1896. Na verdade, no primeiro ano letivo em que ensina na Faculdade de Direito da Universidade de Coimbra aquela cadeira e nas primeiras lições que são compiladas e publicadas por dois dos seus alunos, este objetivo da sua programática política de natureza socialista volta nelas a ser enunciado ipsis verbis (COSTA, 2015: 291).

Portanto, entre o jovem professor universitário e intelectual Afonso Costa e a ação política do ministro da Justiça do Governo Provisório, existe um fio condutor de coerência, em matéria de doutrina política, no sentido de executar a programática socialista de laicização do Estado e da sociedade portuguesas uma vez instaurada a República em Portugal. E recorde-se que este decreto-lei foi ratificado pela Assembleia Constituinte de 1911 e, portanto, os seus princípios vão plasmar-se na primeira constituição republicana que Portugal conheceu. 


\section{A criação do Ministério da Instrução Pública}

Porventura, uma das medidas de reforma política de maior alcance social tomadas pelos governos a que Afonso Costa presidiu terá sido a criação do Ministério da Instrução Pública, no governo de 1913-1914. E podemos considerar que também esta reforma se insere neste objetivo de laicização da sociedade portuguesa pois se a Igreja Católica, a partir de 1911 deixara de fazer o registo civil dos cidadãos, ao mesmo tempo que deixara de ser a religião oficial do Estado português, em consequência este último tinha de universalizar e passar a assumir em pleno as tarefas de instrução pública que durante vários séculos foram assumidas pela Igreja Católica.

Ao nível teórico e doutrinário podemos encontrar, uma vez mais, no intelectual e professor universitário Afonso Costa, designadamente na sua tese de doutoramento, referências programáticas à importância de introduzir reformas profundas e de sentido socializante no domínio da instrução pública, assim podemos ler: "Universalização da instrução geral e profissional, com alimentos, vestuários, e fornecimento de livros, à custa da coletividade" (COSTA, 1895: 97).

Passados dezoito anos, e na sessão do Congresso da República em que apresenta o projeto de lei de criação do Ministério da Instrução Pública, a 30 de maio de 1913, afirma o presidente do governo Afonso Costa:

A criação do Ministério da Instrução Pública faz parte do programa do Ministério a que tenho a honra de presidir, o que equivale a dizer que é uma medida que merece o meu apoio e que julgo indispensável...

Eu entendo que para o desenvolvimento da instrução pública este projeto deve ser aprovado, porque é uma questão de honra para o nosso regime republicano a criação desse Ministério, a que se refere o parecer n. ${ }^{\circ} 38$ (COSTA, 1976: 503).

Três anos depois, com o país em guerra em três frentes de batalha em Angola, Moçambique e na Flandres francesa, e cerca de 100 mil homens a combater e, portanto, numa conjuntura crítica em termos económicos e sociais, o agora ministro das Finanças Afonso Costa, que integra o primeiro governo da "União Sagrada" presidido por António José da Almeida, afirma e propõe na Câmara dos Deputados, na sessão de 18 de maio de 1916, uma meta política importante para o combate ao analfabetismo. A da eliminação do 
analfabetismo em duas gerações, pois considerava, na ordem interna, ser este o principal inimigo da República. Isto tudo a propósito do esforço orçamental que o país tinha de efetuar em matéria de políticas de instrução pública numa conjuntura de um país e de um mundo em guerra:

Quando a república se libertar das despesas da guerra; quando a República puder voltar aos tempos normais, ela retomará a iniciativa, para fazer o mesmo que fez nos primeiros anos da sua fundação, atendendo com o carinho que lhe merece o importante problema da instrução.

Não pode S. Ex. ${ }^{a}$ duvidar disso; a experiência está feita: ela tem feito todo o possível por transformar o ensino superior e secundário; tentou lançar a grande alavanca para a difusão por todo o País do ensino primário é mais do que três vezes aquilo que gastava a Monarquia que caiu em 5 de outubro de 1910 (...) Mas quando amanhã a República puder atacar com ímpeto, com energia, eficazmente, seguramente, $o$ analfabetismo, o inimigo que corresponde ao que agora se nos depara no campo de batalha - nós não trepidaremos e não deixaremos de empregar todos os esforços para o fazer. O meu desejo é que em duas gerações nós possamos extinguir essa chaga horrível que se chama o analfabetismo! (COSTA, 1977: 190-191).

Importa ter presente que foi o Governo Provisório da República que, através da lei de 29 de março de 1911, tornou obrigatório o ensino primário (três anos) para todas as crianças de ambos os sexos. E foi também o mesmo Governo Provisório que instituiu, ao nível do ensino superior, a criação das universidades de Lisboa e do Porto, bem como procedeu à reforma da Universidade de Coimbra, neste caso, através da criação das faculdades de Letras e de Ciências.

\section{A concluir}

Nos dois primeiros governos que Afonso Costa - professor catedrático de Organização Judicial e de Economia Política - integrou, ou presidiu, introduziu na sociedade portuguesa um conjunto de reformas estruturantes, com vista à laicização do Estado e à criação de uma nação modernos.

Num primeiro momento decretou, na qualidade de ministro da Justiça do Governo Provisório da República, no mês de fevereiro de 1910 o Registo Civil Obrigatório, e, em 
abril de 1911, a lei de Separação do Estado das Igrejas. Estes dois decretos com força de lei serão, posteriormente, ratificados pela Assembleia Constituinte de 1911. E em julho de 1913 institui o Ministério da Instrução Pública, mas agora na qualidade de presidente do Governo.

Analisámos, neste breve ensaio, a programática política e doutrinária de orientação socialista reformista que está subjacente ao teor e à redação destes diplomas legais da autoria do governante Afonso Costa, de forma a concretizar reformas que considerava serem cruciais para um Estado e uma nação modernos no Portugal do início do século XX. Considerámos, para este efeito, os seus trabalhos universitários e, entre outros escritos, a sua tese de doutoramento A Igreja e a Questão Social, apresentada em 1895 à Faculdade de Direito da Universidade de Coimbra. Nela encontramos a fundamentação jurídico-política para concretizar, mais tarde, fundamentais e importantes reformas políticas na sociedade portuguesa, enquanto intelectual e universitário que assumiu cargos governativos no início da 1. ${ }^{a}$ República (1910-1926). Ao mesmo tempo, recorremos aos seus Discursos Parlamentares para verificar - cerca de 20 anos depois da defesa da primeira tese universitária que em Portugal aborda a questão social - em que medida é que estes refletem o ideário do professor universitário numa altura em que é governo e que tem a oportunidade de concretizar as reformas legislativas estudadas e que marcaram, indelevelmente, a arquitetura da Constituição Política da República Portuguesa de 1911.

\section{Fontes}

COSTA, Afonso (2015). Apontamentos das preleções do dr. Afonso Costa sobre Ciência Económica e Direito Económico Português, editados pelos seus discípulos José Emídio Soares Costa Cabral \& José Dias. 2. ${ }^{\text {a }}$ ed. Lisboa: IN-CM. (1976). Discursos Parlamentares 1911-1914. Lisboa: Bertrand. (1977). Discursos Parlamentares 1914-1926. Lisboa: Bertrand. (1895). A Igreja e a Questão Social: Análise Crítica da Encíclica Pontifícia De Conditione Opificum, e 15 de maio de 1891. Coimbra: Imprensa da Universidade.

COSTA, Afonso; MARTINS, Germano (1903). A Pronúncia de Joaquim d'Araújo no Processo Esteves Ribeiro. Porto: Tipografia Vapor da Empresa. (1906). O Caso Djalme: Minuta de Agravo de Injusta Pronúncia. Porto: Typ. Central.

LIMA, Sebastião de Magalhães (1985a). Episódios da Minha Vida Vol. I. 2. ${ }^{a}$ ed. Lisboa: Perspectivas \& Realidades. (1985b). Episódios da Minha Vida Vol. II. 2. ${ }^{a}$ ed. Lisboa: Perspectivas \& Realidades. 
(1892). O Socialismo na Europa, com um prefácio de Benoît Malon, o eminente chefe do socialismo científico em França.... Lisboa: Typ. da Companhia Nacional Editora.

MALON, Benoît (1890). Le Socialisme Intégral I: - Histoire des Théories et Téndances Générales Paris: Félix Alcan.

(1891). Le Socialisme Intégral II: Des Reformes Possibles et des Moyens Pratiques. Paris: Félix Alcan.

(1892). Une Préface, em La Revue Socialiste Paris, vol. 2, pp. 79-86. Dispon[ível em:

<http://gallica.bnf.fr/ark:/12148/bpt6k5817559q/f82.image.r=La\%20Revue\%20so cialiste\%20une\%20Préface\%20189202\%20La\%20Revue\%20Socialiste\%201892 \%20une\%20preface>.Acesso: 30 nov. 2016.

\section{Referências Bibliográficas}

ANTUNES, Jaime Moura Botelho (1970). O Registo Civil numa Civilização de Cultura. Braga: Livraria Cruz.

BATALHA, Claudio H. M. (2007). A Difusão do Marxismo e os Socialistas Brasileiros na Virada do Século XIX, em João Quartim de Moraes (ORG.) História do Marxismo no Brasil: Os Influxos Teóricos 1. ${ }^{\mathrm{a}}$ reimpr. Campinas: UNICAMP. ISBN Vol. II.

CATROGA, Fernando (1991). O Republicanismo em Portugal: Da Formação ao 5 de Outubro de 1910. Coimbra: Faculdade de Letras. 2 vols.

Código do Registo Civil e Leis da Família: com índice alfabético organizado por Germano Martins (1911). Lisboa: Imprensa Nacional.

Constituições Portuguesas (1992). Lisboa: Assembleia da República.

COSTA, Mário Júlio de Almeida e Costa; MARCOS, Rui de Figueiredo (2010). A Primeira República no Direito Português. Coimbra: Almedina.

CUNHA, Norberto Ferreira da Cunha (2010). Benoît Malon e o Socialismo, em Ernesto Castro LEAL (coord.) - Republicanismo, Socialismo, Democracia. Lisboa: FLUL.

GARNEL, Maria Rita Lino (2004). A República de Sebastião de Magalhães Lima. Lisboa: Horizonte.

MATOS, Luís Salgado de (2011). A Separação do Estado e da Igreja: Concórdia e Conflito entre a Primeira República e o Catolicismo. Lisboa: D. Quixote.

MOURA, Maria Lúcia de Brito (2004). A Guerra Religiosa na I República. Cruz Quebrada: Notícias.

SEABRA, João (2009). O Estado e a Igreja em Portugal no Início do Século XX: A Lei da Separação de 1911. Cascais: Principia. ISBN 978-989-8131-57-7.

SOUSA, Jorge Pais de (2015). Existiu uma Fração Socialista no Partido Republicano? Os Casos Paradigmáticos de Magalhães Lima e Afonso Costa. ROLLO, Fernanda; AMARO, António Rafael (coord.). República e Republicanismo. Lisboa: Centro República, pp. 75-85. 